\title{
The Status Quo and Countermeasures of Local University Library for Science and Technology Innovation of University Students
}

\author{
Xiuqin Wang \\ Library of Jiujiang University \\ Jiujiang 332005, China
}

\author{
Peng Xiong \\ Library of Jiujiang University, \\ Jiujiang 332005, China
}

\begin{abstract}
To strengthen the national scientific and technological strength, we must create a large number of highquality scientific and technological personnel with particular emphasis on cultivating contemporary university students in science and technology innovation. The scientific and technological innovation activities of university students are an important part of undergraduate teaching in university. With the advancement of the project of outstanding engineers of the education ministry, the requirements of the level and quality of scientific and technological innovation activities of university students are further improved, and the university library needs to be changed in the past to provide efficient service. The role and function of special local universities libraries in university students' scientific and technological innovation needs to be studied. The library must have practical measures and methods to ensure that the university library for university science and technology innovation services can be fast, new and accurate, so that the quality of university library services and university science and technology innovation can be a new level. Therefore, the university library should vigorously support the scientific and technological innovation activities of university students to provide a comprehensive information services.
\end{abstract}

Keywords-local university library; status quo and countermeasures; science and technology innovation; university students

\section{INTRODUCTION}

Nowadays, the comprehensive quality education has become the core of higher education, and the scientific and technological innovation activities of university students are the important contents and practical links of comprehensive quality education. University students as soon as possible to adapt to the community, make a difference, we must learn to have expertise, wide knowledge, with a certain degree of competitiveness, which is not alone classroom teaching and learn a few specialized courses can achieve [1]. And students through the participation in scientific and technological innovation activities, can learn a lot of books, the classroom can't learn things; through diligence information, participate in experimental research, can improve the ability to observe imagination, logical thinking ability, hands-on ability to help students Innovation and skills; through the writing of scientific research reports, papers, can improve the level of writing, scientific expression, professional comprehensive ability, and gradually grasp the method of analysis and demonstration through scientific and technological innovation team cooperation, it can enhance communication skills, oral expression and coordination ability, these are conducive to comprehensively improve the overall quality of students in order to enhance the students' humanistic accomplishment, knowledge conservation, cultivate a sound personality.

University students science and technology innovation activities refers to the students under the guidance of the use of discipline of professional knowledge through independent and independent solutions to practical problems, to complete a theoretical and practical issues in solving problems and completion of the project process, students must adopt new methods and means or solve new problems. The scientific and technological innovation activities of university students are an important part of the practice of university undergraduate level. The level and quality of university students are an important index to measure the level of science and technology of a school student, which directly affects the follow-up course of university students' undergraduate course. The new ideas, new methods and new technologies used in the science and technology innovation activities of university students are derived from the classroom knowledge of teachers, and more from the paper books and electronic journals in the university library. How to make effective use of books and journals in library is the main way to improve the level of scientific and technological innovation activities of university students [2].

\section{DEVELOPMENT STATUS QUO}

University students have no information about the use of information, university libraries have a wealth of information resources, students can always use the electronic reading room, literature search room or through the school library website electronic resources to access a variety of relevant information, which is conducive to students enrich, improve, update the professional knowledge structure, and broaden the academic perspective of students. The library is the second classroom for students to learn independently, and is also an important place for engaging in scientific and technological innovation activities. The library should take the initiative to participate in the scientific and technological innovation and graduation design activities of university students, carry out professional knowledge publicity and education, carry out information training, guide students to effectively use the library resources and improve their professional skills. With the library of 
information technology and professional and technical personnel, so that students as soon as possible to master the computer search literature information methods and techniques, learn to use a variety of powerful, flexible and convenient retrieval system, make full use of network information resources, a comprehensive understanding of disciplines, To improve the level of professional learning and technological innovation.

With the rapid development of information processing technology, the foreign university library, especially some of the world famous university library, although a long history, accumulated rich, but the hardware and software facilities are in place, while the support of scientific and technological innovation also into the daily teaching and research, but the study of university libraries to support university science and technology innovation is not much, but in some experts or papers in a little involved. Such as the use of hypertext technology, can generate new ideas, and different views linked to the use of certain imitation or innovation activities to promote the software package to solve the management problems. Another example is the use of electronic conference system, give full play to the views of librarians to collect innovative ideas. The domestic mainstream view that the university library to provide first-class information services for scientific and technological innovation, because knowledge management and technological innovation has an organic interaction, the literature into the scientific research process, into the process of knowledge creation, through joint and collaboration to achieve resource integration, service integration, service and research process integration.

From the current domestic and foreign reports, especially in the country, most of the current institutions of higher learning are only professional knowledge and computer literature retrieval technology training. With the rapid development of science and technology, the social division of labor to further refine and deepen, relying on the library science and technology service personnel and basic disciplines of professional knowledge retrieval skills can't meet and solve the students in science and technology innovation activities in the emergence of the needs and problems. In recent years, scientific literature retrieval course teaching content is generally based on computer search, but most involved in deep, get little effect. The reason is that most of the teachers' search experience is not enough, the practical ability is poor, not yet master the structure of the search strategy of various methods and techniques; on the subject of professional theoretical knowledge, analysis of less, difficult to cut; Practical solutions to practical problems can't provide effective advice, these are the impact of university libraries to effectively support the scientific and technological innovation activities of university students an important factor.

\section{RESEARCH STRATEGY}

More than $90 \%$ of the world's annual inventions are produced by the patent literature. Moreover, many of the invention results only through the patent literature, and not seen in other scientific literature, is the most authoritative world technology encyclopedia. Therefore, how to make full use of patent literature to promote scientific and technological innovation, to carry out extracurricular science and technology activities of university students, has a very important practical significance [3]. Patent application distribution in each country is shown in Fig.1.

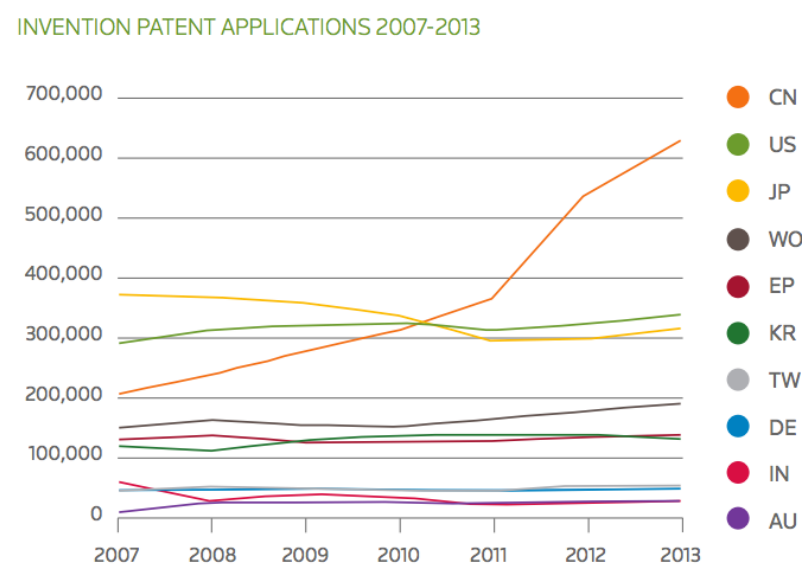

Fig. 1. Patent application distribution in each country

The development of appropriate search strategy is to ensure that the search job search and check the key link. On the basis of determining the search terms, according to the principle of selection and classification, classification-theme combination, test, adjustment and verification, the new search staff can develop a search strategy based on Boolean logic, including the search method, Words, the logical relationship between the search terms and the retrieval steps. Of course, after the identification of the search ideas, the strategy should be noted that: to avoid the limitations of the commissioned party, search should be a comprehensive manifestation of more than one name, tail changes, word order changes, group relations and field settings and other characteristics. The difference between the truncation and the shielding of the different databases in the formula; the idea of the search strategy should not ignore the feasibility of the classification of the search, the recommended classification-the theme of the combination of search, attention to search tools and search time to add and back. The biggest shortcoming of the search is that the searchable documents can't be detected. Therefore, the new search staff should pay attention to the detection effect in real time and revise the search strategy in a timely manner. We should carefully review the search words and words that reflect the essence of the search. The search method is used to retrieve the term of the term of the secondary school, and the new literature library is supplemented and the Internet resources are retrieved [4].

In the process of scientific and technological search, each search new search staff will encounter different professional (Fig.2), different research direction of the subject, for all kinds of new topics, usually use the following database as a basic database must be checked, First, the Wanfang Database of resources under the system, including the database of Chinese journal papers, the database of Chinese scientific and technological achievements, the database of Chinese academic conference papers, the database of Chinese degree thesis, the database of Chongqing Weipu Information Co., Ltd., including the Chinese science and technology periodical database, the other is Tsinghua Tongfang CD shares Co., Ltd. China 
National Journal of the full text of the database, the Chinese degree thesis database, the Chinese academic conference papers database; Fourth, the National Science and Technology Achievements Network [5].

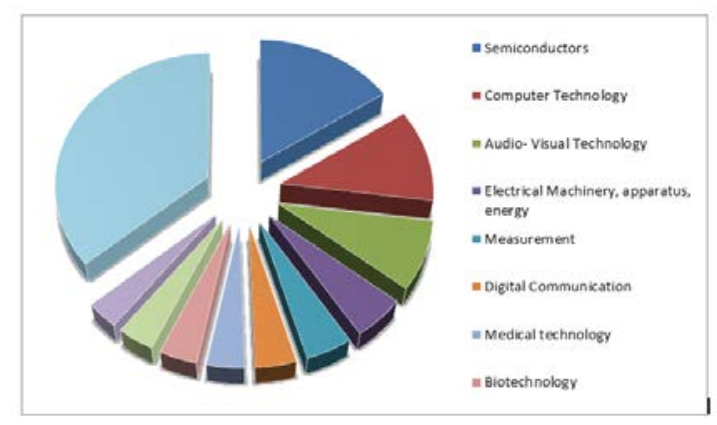

Fig. 2. Patent application distribution in each professional

It is the fundamental duty of the library to use the literature and information data to satisfy the readers' need for literature information to the maximum extent. With the promotion and promotion of the "Excellent Engineer Program" of the Ministry of Education, the university library not only has the traditional consciousness of serving the teaching of university and universities, but also has a new consciousness for scientific and technological innovation, especially the science and technology innovation service of university students. For the students of scientific and technological innovation services than the simple service for the teaching needs of the longer timeliness, more objects, more systematic and in-depth, a wider range of services, labor intensity, higher cost. University library from the teaching services for the teaching and research services, it seems easy to achieve very difficult, we must first establish a strong sense of scientific and technological innovation for university students. Change the passive service as the active service, to understand the school teaching and research development trends, in particular the faculties of faculty, student research work for the university students to provide scientific and technological innovation and guidance services, the library information services into and through the school the whole process of scientific and technological innovation activities [6].

The library directly participates in the teaching and research work of the school, strengthens the tracking of the university science and technology innovation project, and actively provides the information retrieval, the definite service, the document transmission and the reference service for the university student science and technology innovation activity, carries on the information demand investigation and the research work , For students to solve the problem of finding information in the literature, the timely provision of international counterparts in the field of the latest progress, market trends and other information for the library to promote university students to provide scientific and technological innovation activities possible. Library directly involved in teaching and research, the prospects are extremely broad, you can use the mastery of professional knowledge and rich literature and information resources combined with the school teaching and scientific research situation, to take books review, literature interpretation, special information analysis, collation, compilation, Form, take the initiative to display or participate in innovation projects in the library page for teaching and research and innovation activities to provide information protection

The main teaching methods of university students' scientific research skills training courses are mainly classroom teaching. The method of multimedia teaching assessment is to complete three times of literature retrieval. The focus of the examination is whether students are familiar with all kinds of literature information resources and how to retrieve them. In view of the adjusted teaching content, the teaching method of this course needs to be changed accordingly. In the professional database application and related computer retrieval knowledge introduction, is still the main classroom teaching, the use of multimedia teaching. As this part of the main focus on "how to use" and "how to get" information resources, practical strong, so with the progress of the course, the need to arrange several times on the machine, to improve the enthusiasm of students to urge students seriously Understand and digest the classroom knowledge, better familiar with the major domestic and foreign retrieval systems and databases to ensure the quality of teaching.

At present, most of the university undergraduate education is placed in the new campus away from the city center, due to time constraints, school construction and other reasons, teachers generally do not have independent laboratory sites or enough time to communicate with students, so you can use two Methods to guide students to scientific and technological innovation activities. One way is to use the library within a good environment, and students exchange information retrieval means, experience and book information platform evaluation, analysis of the current domestic and foreign academic professional arguments, methods and means of implementation. At the same time, we can also use the site to attract the subject teachers, students point of view thinking to collide, explore, both sides need to support the information through the information platform can be immediately retrieved and indepth discussion, which can form an occasional academic seminars. Another way is to use BBS, e-mail, blog, online chat can introduce and analyze the literature. According to the research topics of teachers and students, the library information platform regularly sends the latest literature on the research direction, so that they can keep up with the research information at any time. At the same time, we can also publish the research information, research trends and important scientific and technological progress in the main research direction of the teachers and students, and also promote the exchange of teachers and students in different professions, increase the understanding and promote the integration and interdisciplinary integration [7].

Technical staff in the search for the prevalence of the search work on the alert, the main reason is worried about the leak, in particular, some technical personnel to declare the patent, due to fear of disclosure after the patent application, in the conversation with the search staff, Patent, or do not want to involve key issues; and some technical staff in the project before the opening of the new search, afraid of their own topics prematurely exposed, or by others to declare and so on. This often makes the search staff can't understand the real needs of 
the information and detours, resulting in the search is always in a passive state, can't fully consider the search strategy. From the actual search work analysis, in the open project, consultation and demonstration stage of the intelligence needs are generally wider than the actual demand, and in the stage of identification and patent search stage of information needs are generally narrower than the actual demand. Therefore, the mutual understanding and trust between the technical staff and the search staff is an important aspect to avoid retrieval errors, but this psychological prevention is often difficult to overcome.

Due to the complexity of the new subject and the search strategy, the collection of documents is also different. Before the literature search, the literature collection should be sorted according to the degree of relevance to the technical points of the subject, and further screening, priority on the relevant literature for comparative analysis. Under normal circumstances sorting and comparative analysis by hand to complete, is a very thoughtful work. With the development of information processing technology, many new literature analysis algorithms and software have been developed. So you can use software tools for correlation analysis and sorting, but the comparative analysis still needs to be done manually. The comparative analysis is to compare the core content of the literature with the technical points, to judge the difference and to define the difference in order to provide a sufficient basis for the conclusion of the search.

From the above analysis we can see that the development of the search strategy and comparative analysis is the key to the search of science and technology. The development of the search strategy depends not only on the technical points of the subject, but also on the performance of the literature resource and the performance of its retrieval tools. Therefore, for the complex multi-disciplinary areas involved in the search for new topics, according to the search results to optimize the search strategy, a number of retrieval. At the same time, in the case of relatively large collection of search results, it is necessary to organize the expert group to analyze or audit to ensure the objective and impartiality of the findings.

In addition, different types of topics need to use different search new search strategy. With the continuous development of science and technology work, will accumulate more and more mature search new search experience, in order to summarize the refinement of the standard search strategy model and standard paradigm, to improve the search efficiency possible. In addition, the study of literature based on mature information processing technology is of great significance to improve the quality and efficiency of scientific and technological innovation.

For complex search projects or results, in addition to the retrieval of professional literature resources, but also should make full use of Internet information resources for retrieval. However, the Internet information resources are relatively large, professional; authoritative can't be guaranteed, only as a supplementary document resource. In addition, the characteristics of the literature resources will also affect the retrieval results and efficiency. For example, the literature resources with the citation database and the index database have higher retrieval efficiency than the literature resources that can only be used for full-text retrieval. At the same time, the retrieval tools provided by the literature resource library have the technical consideration of the specific application environment, should fully consider the characteristics of its search tool [8].

\section{CONCLUSION}

The scientific and technological innovation activities of university students are an important part of undergraduate teaching in university. With the advancement of the project of outstanding engineers of the Ministry of Education, the requirements of the level and quality of scientific and technological innovation activities of university students are further improved, and the library needs to be changed in the past. The library must have practical measures and methods to ensure that the university library for university science and technology innovation services can be fast, new and accurate, so that the quality of university library services and university science and technology innovation can be a new level. Therefore, the university library should vigorously support the scientific and technological innovation activities of university students, to provide a comprehensive information services.

\section{ACKNOWLEDGMENT}

The authors are thankful for the financial support provide by the School-level Teaching and Research Found of Jiujiang University, China (XJJGYB-16-10) and Innovative Entrepreneurship Training Program for National Local University Students, China (201311843007).

\section{REFERENCES}

[1] S. H. Lee; J. Workman; K. Jung, "Perception of time, creative attitudes, and adoption of innovations: A cross-cultural study from Chinese and US university students,” Sustainability, vol. 8, pp. 1193-1195, 2016.

[2] Q. Hu, J. Wu, "The Extracurricular Scientific and Technological Activities of University Students and the Training of Innovative Spirits," Sci. Mosaic, vol. 4, pp. 218-219, 2010.

[3] X. J. Wang, "On the Current Situation and Development Trend of University Library Service,” Educat. Modern., vol. 11, pp. 336-337, 2016. (In Chinese)

[4] X. J. Wang, "The Link Analysis on Websites of Universities Libraries in USA,” J. Library Sci. Jiangxi., vol. 2, pp. 26-30, 2008.

[5] J. S. Magoi, E. Gani, "The Emergence of Digital Libraries Services in Northwest Nigerian Universities: Challenges and Prospects,” Library Phil. Pract., vol. 1184, pp. 1-21, 2014.

[6] A. Ergado, L. A. Gojeh, "Contributory Factors to Library Staff Turnover Pattern and Retention in Academic Libraries of Public and Private Universities in Ethiopia,” Int. J. Library Sci., vol. 4, pp. 81-90, 2015.

[7] B.G. Turner, "Professional staffing in libraries: A Mismanaged Resource,” J. Library Administ., vol. 16, pp. 62-70, 2013.

[8] A. Rasul, D. Singh, "The role of academic libraries in facilitating postgraduate students' research,” Malaysian J. Library Inform. Sci., vol. 15, pp. 75-84, 2010. 